\title{
Global aspirations, local realities: the role of social science research in controlling neglected tropical diseases
}

Kevin Bardosh ${ }^{1,2}$

\begin{abstract}
Neglected Tropical Diseases (NTDs) are both drivers and manifestations of poverty and social inequality. Increased advocacy efforts since the mid-2000s have led to ambitious new control and elimination targets set for 2020 by the World Health Organisation. While these global aspirations represent significant policy momentum, there are multifaceted challenges in controlling infectious diseases in resource-poor local contexts that need to be acknowledged, understood and engaged. However a number of recent publications have emphasised the "neglected" status of applied social science research on NTDs. In light of the 2020 targets, this paper explores the social science/NTD literature and unpacks some of the ways in which social inquiry can help support effective and sustainable interventions. Five priority areas are discussed, including on policy processes, health systems capacity, compliance and resistance to interventions, education and behaviour change, and community participation. The paper shows that despite the multifaceted value of having anthropological and sociological perspectives integrated into NTD programmes, contemporary efforts underutilise this potential. This is reflective of the dominance of top-down information flows and technocratic approaches in global health. To counter this tendency, social research needs to be more than an afterthought; integrating social inquiry into the planning, monitoring and evaluating process will help ensure that flexibility and adaptability to local realities are built into interventions. More emphasis on social science perspectives can also help link NTD control to broader social determinants of health, especially important given the major social and economic inequalities that continue to underpin transmission in endemic countries.
\end{abstract}

Keywords: Neglected tropical diseases, Applied social sciences, Implementation research, Social determinants, Community participation, Policy, Global health, Sociology, Anthropology

\section{Multilingual abstracts}

Please see Additional file 1 for translations of the abstract into the six official working languages of the United Nations.

\section{Background}

Influenced by certain ecological conditions and transmitted through various vectors and animals, Neglected Tropical Diseases (NTDs) are a heterogeneous group of some 17 parasitic, bacterial, viral and fungal infections that

\footnotetext{
Correspondence: bardosh_kevin@hotmail.com

${ }^{1}$ Centre of African Studies, School of Social and Political Science, College of Humanities and Social Science, The University of Edinburgh, 58 George Square, Edinburgh EH8 9LD, UK

${ }^{2}$ Division of Pathway Medicine and Centre for Infectious Diseases, School of Biomedical Sciences, College of Medicine and Veterinary Medicine, The University of Edinburgh, Chancellor's Building, 49 Little France Crescent, Edinburgh EH16 4SB, UK
}

burden the poor and marginalised in developing countries where they cause much human suffering and poverty. One billion people, referred to as the "bottom billion", are estimated to be infected by the seven most prevalent NTDs (schistosomiasis, trachoma, soil-transmitted helminths, lymphatic filariasis and onchocerciasis) in over 100 countries [1-3]. Taken together, NTDs are thought to be second to HIV/AIDS in terms of infectious disease burden yet they receive only a small proportion of development assistance allocated to health [4]. The impact of these infectious pathogens is often difficult to quantify due to under-reporting, focal clustering, poly-parasitism, diverse morbidity, stigmatisation and multifaceted influences on local livelihoods. Although notable gaps in control and treatment tools remain, many NTDs have a practical "toolbox" of control options; this ranges from 
mass anthelmintic treatment of populations, vector control, active case detection and treatment, targeting of the animal reservoir, environmental modification and improvements in housing, water, hygiene and sanitation [2].

Since the early-2000s, advocacy efforts have increased greatly for NTDs, and these "forgotten afflictions" have become somewhat less neglected in the global health landscape [3]. Much of this new attention has been driven by policy narratives that have framed NTD control as an avenue towards addressing global inequity and poverty through cost-effective but big impact interventions - what have been termed "low-hanging fruit". Such advocacy has relied heavily on the "value for money" of the integrated control of parasitic worms through mass drug administration (MDA) [5,6]. NTD control has been linked to meeting multiple Millennium Development Goals (MDGs); numerous public-private partnerships, greater funding into scientific research and drug/diagnostic product development, significant donation of medicines by the pharmaceutical industry, and new and reinvigorated donor and country programmes have followed. Illustrative of this global momentum, the World Health Organisation (WHO) Director-General, Dr Margaret Chan, has called NTD efforts a "Cinderella tale...of moving from rags-toriches" [7]. Both the London Declaration in 2012 and a landmark WHO resolution in 2013 signified the political and financial commitment of endemic country governments and key donors (i.e. USAID, Gates Foundation and DFID) to support ambitious new targets for control and elimination set for 2020 [8,9]; these are summarised in Table 1 for all 17 major NTDs.

Despite this enthusiasm, numerous challenges to meeting these new targets exist. These involve both technical questions about the efficacy of existing tools as well as operational issues in moving global health interventions from international boardrooms into socio-economically and politically marginalised communities. Invoking the classic dichotomisation between "top-down" and "bottomup" public health approaches, Spiegel and others [10] have argued that current NTD programmes over-prioritise narrow technical solutions at the expense of prevention efforts and broader engagement with the social determinants of health. Debates have emerged most visibly in the rapid scaling-up of integrated MDA, which treated a reported 887.8 million people in 2009 [3,11]. Some have questioned the scientific evidence-base of the MDA strategy [12], potential development of drug resistance [13], the feasibility of integrating several existing programmes [14], the effectiveness of using unpaid volunteers [15], negative effects on health systems [16], and local resistance and non-compliance with free treatments [17-21]. In the absence of integrating MDA with other strategies (i.e. water, hygiene and sanitation improvements, case management and vector control) others have argued that underlying causes are left unaddressed, perpetuating a "drug dependence" on preventative chemotherapeutic treatments [22-24]. The WHO itself has acknowledged a number of complex risks that threaten the feasibility of meeting the 2020 NTD targets; these range from socio-political trends, challenges in vector control, lack of local health system capacity, various scientific gaps and the limited amount of funding being allocated for implementation research [2].

Current debates reveal that despite policy narratives centered on the poverty-inducing effects of NTDs, relatively little research is being promoted, or undertaken, on how the context of poverty and marginalisation influences the effectiveness and outcome of control/elimination/eradication programmes [25]. Diseases of poverty are, by definition, both drivers and manifestations of poverty. They reflect not only individual risk factors, but larger structural inequalities in access to health services, infrastructure, food security, education, political voice and markets that drive poverty and maintain social and economic exclusion [26,27]. Within these resource-poor settings, this context of poverty will invariably dictate how NTD interventions are implemented as well as the particular ways in which disease control technologies are adopted and used (or not used) by local health systems and target populations. In short, the same povertyinducing factors that drive NTD transmission present various context-specific challenges to controlling them.

There is an increasing emphasis in global health to address the gap between the scientific efficacy of tools and strategies and their practical translation and impact into different local contexts - the so-called "implementation gap". Optimising the impact of existing programmes is arguably one of the most cost-effective funding strategies that international agencies and national governments can take [28]. In the field of NTDs, the Special Programme for Research and Training in Tropical Diseases (TDR) - funded by UNICEF/UNDP/ World Bank/WHO - has coordinated and funded much ground-breaking implementation research going back to the 1970s. Through training and small grants, TDR has stimulated the development of social and economic research into tropical diseases, brought social scientists into collaborative arrangements with biomedical scientists (especially on malaria, schistosomiasis and onchocerciasis) and worked to highlight otherwise overlooked areas, such as the importance of gender and community participation [29]. Acknowledging this contribution, two recent reports partially funded by TDR - Implementation Research for the Control of Infectious Diseases of Poverty in 2011 and The Global Report for Research on Infectious Diseases of Poverty in 2012 - have emphasised the need for greater emphasis on implementation research in NTD control [30,31]. These reports were 
Table 1 Major NTD control targets set for 2020 by WHO

\begin{tabular}{ll}
\hline NTD & WHO Target [1] \\
\hline Dengue & "With new tools for diagnosis and vector \\
& control, better case management and focused \\
& research....an integrated vector management \\
& approach should reduce rates of morbidity by \\
& at least 25\% and of mortality by 50\% by 2020."
\end{tabular}

Rabies

"Elimination of human rabies transmitted by dogs and dog-to-dog transmission is achievable by 2015 in all endemic areas in Latin America; and by 2020 in all affected countries in WHO's South-East Asia and Western Pacific regions."

Trachoma "...global elimination goal by 2020... By 2020 all countries will have achieved the UIG and be free from blinding trachoma as a public-health problem, and by $2020,75 \%$ of countries will have been verified as free from blinding trachoma as a public-health problem."

Buruli ulcer

"WHO aims to cure $70 \%$ of all cases with antibiotics in all endemic countries by 2020.

Endemic

treponematoses

Leprosy

Chagas disease

Human African Trypanosomiasis

Leishmaniasis

Cysticercosis

Echinococcosis trematode infections

Lymphatic filariasis
"Elimination of yaws in Africa is feasible by 2020, therefore leading to global eradication"

"Vigorous case finding and treatment would lead to global interruption of transmission by 2020."

"A milestone will be reached when peridomiciliary infestation has been eliminated in Latin America by 2020."

"...eliminate the disease in $80 \%$ of foci by 2015 and achieve elimination in 100\% of foci by $2020 . "$

"WHO aims to detect at least 70\% of all cases of cutaneous leishmaniasis and treat at least $90 \%$ of all detected cases in the Eastern Mediterranean Region by 2015. With sustained efforts on the Indian sub-continent, 100\% casedetection and treatment of visceral leishmaniasis

"A validated strategy for the control and elimination of Taenia solium taeniasis/ cysticercosis will be available by 2015; and interventions for control and elimination scaled up in selected countries in Africa, Asia and Latin America by 2020."

"Dracunculiasis is now on the verge of eradication."

"Pilot projects to validate the effectiveness of echinococcosis/hydatidosis control strategies will be implemented in selected countries by 2015 . Scale up of interventions in selected countries in Central Asia, North Africa and Latin America for control and elimination as a public-health problem will be in place by 2020."

"By 2020, 75\% of the at-risk population will have been reached by preventive chemotherapy and morbidity associated with foodborne trematode infections will be under control in 100\% of the endemic countries."

"By 2020, 100\% of all endemic countries will have been verified as free of transmission or will have entered post-intervention surveillance." is feasible by $2020 \ldots "$
Table 1 Major NTD control targets set for 2020 by WHO (Continued)

\begin{tabular}{|c|c|}
\hline Onchocerciasis & $\begin{array}{l}\text { "It is currently estimated that, by } 2020,12 \text { APOC } \\
\text { countries and } 11 \text { ex-OCP countries may have } \\
\text { achieved elimination, out of a total of } 31 \\
\text { countries affected..." }\end{array}$ \\
\hline Schistosomiasis & $\begin{array}{l}\text { "...could be eliminated as a public health } \\
\text { problem in multiple countries in Africa by 2020, } \\
\text { and globally by 2025." }\end{array}$ \\
\hline $\begin{array}{l}\text { Soil-transmitted } \\
\text { helminthiases }\end{array}$ & $\begin{array}{l}\text { "...75\% coverage will be reached in all } \\
\text { countries by 2020." }\end{array}$ \\
\hline
\end{tabular}

built explicitly on the conceptual integration of human, animal and ecosystem health as articulated by the "One World, One Health" movement and outlined a new trans-disciplinary vision for addressing, among other things, the social determinants of health and illness and hence promoted the greater involvement of social scientists [32].

However there are a number of difficulties in realising this agenda. As with global health more generally, funding for NTDs is heavily concentrated on biomedical research and, to a lesser degree, pharmaceutical industry support for drug development [10,33,34]. Requiring multidisciplinary teams and new sorts of methodologies, part of the "neglect" of implementation research has to do with the fact that it often not considered a "serious science" [34-36]. The actual translation of such research into more effective interventions is also complex and uncertain. Research on gaps between policy, programmes and target populations regularly encounter barriers to being incorporated into particular programmes or the larger health system landscape; hence simply conducting research on the "implementation gap" does not mean operational practices will change and be improved.

One of the major dimensions to the implementationNTD nexus relates to the level of involvement of social scientists - particularly sociologists and anthropologists - in interventions. Disjunctions between biomedicine and social research have traditionally been maintained by disciplinary (and epistemological) differences as well as working norms, systems of reward and grant funding cycles [36-39]. Despite efforts dating back to the 1970s [29,39-41], a number of recent publications (some commissioned by TDR itself) have criticised the contemporary NTD landscape for a lack of social inquiry and consideration of local contexts in devising and implementing control programmes $[17,21,25,42-45]$. In many ways, these publications have reiterated old debates about the limited cross-fertilisation between biomedical and social scientists. Allotey et al. [43] summarily stated that "research and interventions for neglected tropical diseases, largely neglect the social 
and ecological contextual, factors that make these diseases persist in the target populations" and that social research, when it is conducted, is largely "hand-maiden" to biologically-defined solutions and perspectives. Another recent paper claimed that the epistemic communities working on NTDs and social determinants have been largely "passing in the night" with little direct contact [44]. A bibliographical analysis of research publications emphasised that the social sciences are being "underprioritised" and "neglected" by the contemporary NTD research and programme landscape [42]. Tensions have most vividly been shown in a series of publications, including in The Lancet (the prestigious UK medical journal), between anthropologists, who found community resistance to MDA in Uganda and Tanzania, and some longstanding NTD advocates based at the WHO and elsewhere $[3,11,17,45]$.

The aims of this paper are to move beyond polarising statements about the lack of social science research on NTDs; the paper attempts to stimulate critical debate about what types of studies have already been conducted and what they show us about how applied social inquiry can contribute towards supporting the 2020 targets. Using the NTD-specific literature, the paper explores some of the major challenges facing planners, implementers and communities in sustainably controlling NTDs and the barriers and bridges that require more consideration. Moving conceptually from the global into the local, it maps out five priority areas where applied sociology and anthropology can best contribute to an implementation research agenda, including on policy processes, health systems capacity, community responses to interventions, education and behaviour change and community participation. Methodologically, the paper does not attempt to systematically analyse the existing literature, which would have proven to be a more complex task considering the 17 NTDs. Rather it builds on recent reviews of social science research and NTDs mentioned above, including a bibliographical analysis of existing literature for chikungunya, dengue, visceral leishmaniasis, and onchocerciasis [42], NTDs and social determinants [27] and NTDs and community participation [41]. It supplemented these data sources with secondary bibliographic searches of key journals and other important publications, aiming to reference some of the most insightful and representative academic publications that engage with the challenges of NTD interventions. The paper mainly focuses on research published since 2000 .

\section{Review}

\section{Policy processes}

The first priority area for social research involves policy processes, which remain poorly understood in most developing economies and involve various components; a useful framework developed by the Institute of Development Studies (IDS), University of Sussex [46], divides policy processes into discourses/narratives, social networks and politics/interests. Tied to a specified set of actors used to mobilise resources, policy narratives often frame issues in simplistic ways to reduce uncertainty and enrol support. These are based on specific underlying assumptions that create boundaries around an issue, define the limits of action and what/who is to be included and excluded.

Neglected diseases largely persist in countries with financial and human resource constraints. In a unique study, Spiegel et al. [47] reported that a central bottleneck in dengue control programmes related to value differences between stakeholders and the ability for institutions to adapt and learn from operational mistakes. More generally, bureaucratic norms and weaknesses in management have been noted as one of the major binding constraints in global health; highlighting this generally overlooked but important area [48]. Kabaterine et al. [14] alluded to some of these complexities in the African context when they noted that restructuring several vertical programmes into one integrated MDA programme could "cause resentment among managers, in extreme cases leading to obstruction and other difficulties in managing the process". Such human resources issues are embedded within different socio-cultural, economic and political processes that shape the governance and delivery of healthcare services [49].

Understanding national policy contexts is essential to adapting programmes from the global to national/local level. Civil service and health system reforms (i.e. sectorwide approaches, decentralisation and liberalisation) have been shown to present unique challenges; as noted by Cairncross et al. and Miri et al. in their analysis of the lengthy process of dracunculiasis eradication in Ghana and Nigeria [50,51]. National policy contexts also foster differences in ministerial relationships between sectors that complicate inter-sectoral programmes, especially important for zoonotic NTDs such as rabies, cysticercosis, echinococcosis and Rhodesian sleeping sickness, as well as multi-sectoral programmes on water, hygiene and sanitation [52-54]. Complex fiscal relationships exist between different levels of government both vertically (from central to local) and horizontally (between ministries). Even where legislation exists, mechanisms to ensure intersectoral financial and operational responsibilities are often lacking - shown in a recent study on a dengue outbreak in Mexico [55]. Pharmaceutical liberalisation and the lack of state regulation can also contribute to inherent tensions between public health and other actors in the private health system - see Bardosh et al.'s analysis of the veterinary pharmaceutical market in sleeping sickness endemic areas of Uganda [56]. 
NTD governance arrangements involve many actors outside the realm of the state: international agencies, universities, the private sector, philanthropic foundations, international and national non-governmental organisations, community-based organisations and others [57]. Funding sources, institutional capacity and personal relationships are central to driving partnerships forward, where partners have different strengths and weakness, and power dynamics influence operational practices [58]. While non-state interventions implemented, for example, by NGOs, universities and the private sector can sometimes circumvent the hurdles of state bureaucracies and resource-constraints, long-term sustainability often demands state involvement or integration within the general health system; leaving the state behind, without capacity building, can create long-term problems in sustainability.

These various social contexts present multifaceted challenges to the scaling-up process. As discussed by a recent paper describing a USAID integrated MDA initiative in multiple African countries, scaling-up can involve: organising a central coordination mechanism, stakeholder engagement, situational analysis, action and work plans, funding gap analysis, disease mapping and defining monitoring and evaluations criteria [59]. While constraints are inevitable, their particulars are rarely subject to analytical scrutiny and the little attention given to monitoring and evaluation more generally risks limiting learning and adaptation [60]. The need for programmes to "look good" in order to attract donor-driven grant cycles have been noted for structuring what issues are researched and how, limiting opportunities to explore and discuss complex social and operational challenges [45].

Furthermore, the desire for results by donor agencies over short project cycles have been noted to push programmes to go to scale too quickly and lead to poor mobilisation, education and support for field staff. While a major challenge is enabling flexibility to country-contexts in NTD programmes that often have a global remit, arguably more challenging is adapting to socio-cultural, political, economic, infrastructural and environmental differences between and within districts. Studies show that despite trends towards decentralisation in local government in many endemic countries, feedback and responsiveness to local needs within the general health systems are limited; this is perpetuated by planning and managerial spheres being heavily centralised with little decision-making capacity at the district level - as shown by recent NTD studies in Tanzania, for example [61-63]. Transcending the classic "transplantation" problem in global health - where standardised approaches do not allow for context-specific strategies - requires thinking beyond the technology transfer model to engage more directly with local needs and the complexity of the scale-up process [64].
More than other areas, there is a dearth of research on policy processes for NTDs. Analysis of the interrelationships between global and national policy contexts, institutional and organisational norms and values, the devolution of power and information sharing, stakeholder incentives, and the potential bottlenecks in service delivery networks clearly require more attention. Such research can provide valuable information to help manage NTD programmes, build adaptability and learning into the scale-up process and exploit the strengths of different policy actors. With a variety of methodological and conceptual frameworks available, systematic health policy research could play important roles in informing NTD policy development and programme implementation $[46,65]$.

\section{Programmes and health systems}

The second, albeit interrelated, priority area involves the interface between programmes and health systems. Functioning primary healthcare systems are recognised as essential to NTD control [66]. However neoliberal reforms in the late 1980 s to "roll back the state" led to drastic reductions in health (and veterinary) sector expenditure in many developing countries [67]. At the district-level, programmes operate where human resources, information systems, essential drugs, basic infrastructure and supplies are often extremely limited. Weak state and patron-client relationships place locallevel staff between the interests of the local and the national/global. The wider anthropological literature on international development shows that policy itself has a precarious influence on the operational practices of development projects - including NTD interventions - which are shaped more by organisational demands, norms and relationships at the local level $[68,69]$.

NTD programmes make use of health systems in three general ways: integration within health services (used for many leprosy programmes), structures completely outside (most mobile sleeping sickness screening services), and programmes organised by the central-level but carried out by district staff (many current integrated MDA programmes) [70]. There are both positive and negative impacts of such programmes on the general health system, ranging from effects on leadership and governance, health information systems, financing, infrastructure and supplies, workforce and service delivery [71]. One way to avoid negative impacts is to take account of resource-limitations and working norms before projects attempt to "piggy-back" on existing delivery networks; as shown by a scoping study on the feasibility of Human African Trypanosomiasis elimination in Zambia [72].

The few in-depth studies on the relationships between NTD programmes and health systems have shown different results. Baker et al. [73] reported a retrospective 
mixed methods study on two years of lymphatic filariasis integration in the Dominican Republic. This required adapting to national health sector reforms and decentralisation, including using community volunteers to account for staff shortages. The authors reported that integration substantially increased coverage of MDA (despite initial difficulties) and strengthened information systems and community engagement in the health system, partially because key stakeholders were well prepared for the integration process. Advocates of community-driven ivermectin treatment for onchocerciasis have argued that the approach strengthens primary healthcare by giving control of decision-making to communities, albeit providing the necessary resources and support requires multiple years of re-trainings [74]. In contrast, studies on leprosy programmes have shown the reluctance of control staff to take on extra responsibilities, the inadequacies of short trainings and variations between districts/regions based on the quality of the health system [75-77].

The few studies on MDA have also revealed significant challenges. Cavalier et al. [16] documented the disruption of access to general healthcare during integrated MDA in Mali and the lack of funds for institutional strengthening. A further ethnographic study in Tanzania commented on how district-level health staff considered handling multiple NTD interventions simultaneously as more of a burden than a cost-saving strategy [21]. Cairncross et al. [50] discussed 13 years of stagnation in dracunculiasis eradication in Ghana (due partially to the implementation of a sector-wide approach, government decentralisation and staff transfers) while Balen et al. [78] drew attention to more subtle social equity issues in China for schistosomiasis, where barriers to treatment were driven by the lack of medical insurance among the poor, despite a well planned and integrated programme.

Integrating programmes into the general health system is in many cases necessary and desirable. This requires vertical programme managers to navigate the political landscape of the health system, foster clear understandings of roles and responsibilities, and provide strategic training, resources, supervision and support. Local health systems remain frontline mediators between communities and neglected pathogens long after many donor-funded projects end; hence examining their needs, capacities and contexts should form an integral component of any comprehensive NTD programme.

\section{Community responses to interventions}

A third key area for social inquiry to support NTD control involves community responses to interventions, particularly compliance and resistance. Among others, the work of the political scientists James Scott $[79,80]$ has shown how the intended beneficiaries of scientific interventions, including global health interventions, challenge dominant knowledge claims through local resistance, avoidance, noncompliance and strategic accommodation. Despite the best of intentions, technological interventions seldom involve the unproblematic application of scientific tools to local settings but invariably provoke acts of reinterpretation as they engage with local perceptions and experiences.

On the one end, the NTD literature shows that interventions are mediate by access barriers embedded within geography, delivery schedules and differences between population sub-groups. In a qualitative study, Mpanya et al. [81] noted the discrepancies between the schedule of a HAT mobile screening team and the movements of diamond miners and farmers, which significantly lowered the number of people willing to be tested. The need to tailor delivery strategies to different sub-populations is a ubiquitous finding of most social studies; as shown in the influence of gender on MDA [82], compliance of pastoralists with canine vaccination for rabies [62] and schistosomiasis control among fisherfolk [19]. Numerous other access barriers have also been noted. Omedo et al. [83] in Kenya argued that better coverage for schistosomiasis control would be achieved if MDA were carried out during the harvest period to correspond with food availability to reduce side-effects. Coverage of ivermectin treatment has been low due to discontinuities between the working hours of health personnel and farming schedules - a partial impetus for allowing community volunteers to determine the period of treatment [74]. Furthermore, the success of case detection strategies and surveillance, for example in visceral leishmaniasis control in South Asia [84], can depend substantially on whether communities prefer public or private health systems and how projects engage with different providers. Clearly, conducting such studies prior to a biomedical research or control programme can avoid many costly (and unnecessary) operational blunders.

However barriers to community compliance go well beyond these more easily remedied operational issues and a growing body of literature on "local resistance" to global health interventions has emerged [85-87]. Resistance is often deeply rooted in local frames of reference, tied to social networks and related to wider sociopolitical issues. Local understandings of disease, relationships to government officials and the state, and past experiences with development projects play important mediating roles. For example, local perceptions about drug toxicity, lack of confidentiality during screening procedures and local beliefs about the costs of treatment contributed to resistance to HAT screening in the DRC [81]. Hastings [87] described how riots occurred after an MDA programme in Tanzania due to fears that it was a covert sterilization campaign, which resonated with local 
anxieties questioning the intentions behind westerndriven development projects. In fact, local resistance to MDA has been reported in numerous studies in the last few years [17-21,88-95]. A review of research for lymphatic filariasis control identified: local fears over treatment and side-effects, individual characteristics (including mobility patterns), knowledge and awareness, prior experiences with MDA and the training, motivations and characteristics of distributors [90]. Observing the poor compliance rates for MDA in Ugandan schools, Muhumuza et al. [94] proposed increasing health education, teacher motivation and providing snacks. Others have questioned the effectiveness of using teachers and community volunteers where notions of medical expertise are exclusively tied to health professionals $[87,95]$. A more complicated picture was illustrated by ethnographic fieldwork done by Parker and Allen [17-20] who remarked on the need to link MDA drug distribution to more holistic control approaches to legitimise it to reluctant community members - confused about why they should swallow tablets when disease drivers remain unaddressed.

Understanding livelihood patterns, migration, health seeking behaviour, local knowledge and others social processes at play among the "bottom billion" can help tailor programmes to enhance community acceptability. A major issue is the level of trust between recipient communities and field staff and delivery networks, and the degree to which interventions are tailored to local concerns, perspectives and needs. Giving greater scope to local voices would address many, but perhaps not all, cases of "active resistance". There is a need to abandon the simplistic, but safer, interpretation that noncompliance is primarily about "lack of awareness" and reflect more on the nature of the programme strategies used and their wider socio-political context - what has been called the political epidemiology of disease control [96].

\section{Educating publics, changing behaviours}

While risk behaviours have been widely emphasised by social science studies on different NTDs $[97,98]$ little research has directly and systematically explored health education, despite its importance for addressing noncompliance. For example, the studies referred to above on MDA are unanimous that certain information is fundamental to accompany MDA but have not been readily incorporated into campaigns: Why do some experience side-effects but others not? Why is praziquantel given by height and not weight? Why do people without symptoms have to take drugs? Why is the programme not addressing water and sanitation? Education strategies play a double role. They not only promote greater community compliance by making people aware of the value of participating in a given programme but they can also be used to promote fundamental behaviour changes with long-term implications.

There is a large literature on the complexities of devising and tailoring education and public engagement strategies for health issues in developing country contexts; the literature emphasises that messages should not only be culturally acceptable but "culturally compelling" [99]. In a revealing study on malaria nets in Africa, PanterBrick et al. [100] showed the need to reinforce simple messages over time using different mediums, gain community support and focus on positive outcomes while also addressing constraints to people's agency. Similarly, based on his experience with guinea worm, Brieger [101] emphasised moving beyond didactic methods to include skills development, knowledge acquisition and active community involvement.

Few studies explore how existing national programmes educate their publics for NTDs and how education campaigns can move beyond small-scale, donor-funded research projects. An ethnographic study in Cambodia on the national dengue control program delivery at schools, health centres and villages is a rare and insightful example. Under-funded, irregularly implemented and seldom evaluated, Khun and Manderson [102] reported on various operational shortcomings, including little training or incentives for health staff and teachers and confusing messages that did not engage with local constraints to behavioural change. The authors recommended schools engage in community-based vector control outreach activities to move beyond an otherwise passive education model. The work of Parker and Allen [17-20] is also informative. In Uganda and Tanzania, they found that adults were increasingly rejecting free treatment for schistosomiasis, lymphatic filariasis and soil-transmitted helminths. Part of this involved health education used by volunteers, school teachers and government officials that did not engage with real and imagined fears of side effects based on local aetiological concepts and suspicions about the motivation of the programme. Similarly, Hastings [87] revealed how health education accompanying an MDA programme in Tanzania did not provide sufficient time for dissemination to parents and local leaders. Influenced by time and budget restrictions, Burke [103] also noted the "top-down" planning process used in Togo during an integrated MDA health education strategy which did not engage with gender dimensions, local understandings of disease, drug sideeffects and the rationale behind MDA, although community volunteers did adapt guidelines in practice.

Given emerging critiques of non-compliance to NTD interventions, especially MDA, there is an urgent need to explore how national NTD programmes are engaging with community perceptions in health education and 
how future educational strategies can address local concerns. Although most of the NTD literature shows positive increases in knowledge through health education [104-106], few studies explore the opportunities and challenges involved in how education can be used to actually change behaviour - see El-Katsha and Watt's superb study on schistosomiasis in Egypt (with a focus on gender differences) for an example [107]. There are deeply imbedded barriers to behaviour changes that need to be considered and incorporated into educational strategies [108]. For example, the tensions between the public and private goods aspect of vector control has been noted for why people, otherwise knowledgeable about prevention practices, do not practice them $[109,110]$. Important differences between (sub-) populations may require different strategies, based on gender, age, wealth and livelihoods $[111,112]$. These differences maintain power dynamics at the community-level that need to be understood. Broader disjunctions between "knowing" and "doing" are also structured by poverty, livelihood patterns and locally embedded socio-cultural processes, which need to be more thoroughly accounted for during the planning of interventions. Finally, there is also clearly a need to consider the fact that behaviour change, even within a well-designed programme, may be unlikely to occur in politically and economically-marginalised communities, at least for certain types of embedded behaviours. Broader changes in economy, politics and social organization may be needed as prerequisites for effective, long-term disease control.

\section{Fostering participation, tailoring programmes}

The last priority area, intersecting with the others, relates to community participation, which is often polarised between dismissal and romanticisation. Engaging with communities occurs in different ways depending on envisioned goals and outcomes but is arguably the most essential aspect of addressing local resistance and fostering behaviour change. Rifkin [113] divided community involvement into a spectrum from passive compliance oriented around a "target framework" to active involvement in priority setting and planning focused on "empowerment processes" where planners and implementers take on roles as facilitators. The NTD literature shows this full spectrum of participatory strategies; for example, mobilising households in triatomine surveillance [114], controlling schistosomiasis through changes in water contact [115] and irrigation system cleaning [116], volunteer networks for guinea worm eradication [117], and grassroots task forces for dengue control [118]. This literature shows us that without a sound understanding of community dynamics guiding intervention planning there is a risk that planners and implementers pursue reductionist strategies.
"Communities" rarely adhere to geographical locations, which are composed of a diversity of sub-groups with differences in needs, capacities and constraints. This may present challenges for approaches that seek the broad involvement of the community; for example, community-led total sanitation (CLTS) - a participatory sanitation programme where people are encouraged to build their own locally-sourced pit latrines and recently promoted by NTD advocates - may face challenges in addressing entrenched gender dynamics in Africa [119]. While compelling, the wider development literature points to numerous potential shortcomings when participatory interventions are scaled-up from small-scale successes: the tendency for marginalized groups to be excluded, facilitators to dominant the process, lack of awareness of conflicting interests at the community-level, pressures for quick results and the use of self-interested intermediates $[120,121]$. Perhaps more problematic is the notion that community participation involves communities "doing it themselves" which overlooks the fact that such interventions essential create new social networks dependent on the implementing agency. The failure of many community-driven tsetse trap projects popular in the 1990s and 2000s is one example [110]. People were willing, to varying degree, to contribute money, time and effort but activities ceased in the absence of inputs and state/NGO/academic coordination [122,123]. While some have argued that technical experts hampered success by never truly devolving ownership [123], poor farmers are also reluctant to invest scarce resource and time into a public good, especially once vector populations decline.

Past experiences with tsetse trap projects, and many other participatory NTD efforts, questions the notion that sustainability equates to the cessation of support from the outside. Clearly, economic and political realities reduce the resources, time and capacity of "the bottom billion" to participate in disease control and seek medical treatment in dynamic ways. Although this questions the idealistic notion that community members can identify, prioritize and resolve their own health problems [41], it also reinforces the need for community-led initiatives to help build societal resilience. Rather, sustainability should be evaluated by how projects facilitate continued linkages between communities and their local health system, and other actors. One way to do this is to integrate acceptable and efficacious strategies that resonate broadly with the lives of poor people through addressing sanitation, water, primary healthcare, housing and environmental management instead of narrowly focussing on one specific pathogen - NTDs are only one problem among many facing the lives of the poor.

Furthermore many successful programmes are built not on mass community mobilisation but on enrolling the support of key actors at the community-level. Much 
debate has ensured about what type of inputs should be provided and the level of devolved priority setting and planning. The most well documented example for an NTD involves community-directed ivermectin treatment for onchocerciasis in Africa, emerged from a lengthy process of operational trial, error, learning and adaptation since the 1980s [74]. Volunteers are selected by the community, trained and given ownership over determining the period and mode of annual treatment. Although financial incentives are rarely provided, social status (recognition, self-fulfilment and political influence) and meals, books and labour from recipients act as important non-monetary incentives $[124,125]$. The motivation and support offered to volunteers clearly impacts coverage. Emukah et al. [126] reported on the high drop-out rate of distributors in Nigeria (at least 35\%) related to a lack of incentives and supervision, long travel distances, other duties and poor supply of ivermectin. Other studies have commented on the fact that higher coverage is maintained by volunteers living closer to the communities they serve and being responsible for fewer households [124,127]. The involvement of women in patriarchal societies is also a significant operational issue [128] while volunteers can be overburdened and/or dissuaded by other community-based activities (such as polio vaccination) where money is provided [129]. Variations between countries based on the strength of the health system have also been noted [124].

There are a number of areas for implementation research to explore innovative and practical ways for community participation to enhance NTD efforts. The first is how existing community participatory strategies, for example volunteer networks in ivermectin, can strengthen primary healthcare which, despite much discussion, has not been the subject of in-depth social studies. Arguably, greater resources and support are required to be channelled to the community-level for this to be realised. Second, there are few examples of projects that seek to engage different actors in multi-stakeholder strategies where different concerns and interests are incorporated into the planning process. For example, a dynamic 10 year action-research process for the control of cystic echinococcosis in Nepal moved from biomedical strategies to focussing on garbage collection policy and urban renewal through a stakeholder engagement process [130]. Other multifaceted examples include the control of dengue in Latin America [131] as well as a 15 year partnership between mobile pastoralists, government authorities and the Swiss Tropical and Public Health Institute in the Sahel [132]. Studies should more systematically evaluate their feasibility and benefits as a way to strengthen relationships between communities, social service providers and donorprojects. Third, there is a widespread lack of acknowledgement of the types of participatory interventions that are most effective in NTD control and how they can be scaleup efficiently. To address this, social science research is needed to devise new methodologies to measure behaviours, change processes and social impact in order to provide the evidence-base for incorporating community participation into mainstream NTD programmes, while also avoiding the tendency for participation to become a technocratic, tick-the-box exercises [133]. Fourth, there remains much scope to explore the shortcomings of how contemporary interventions are engaging communities, where social scientists can address barriers and propose new strategies, preferably as part of a long-term engagement strategy in collaboration with biomedical and public health experts [134].

\section{Conclusions}

This paper has discussed a range of social dynamics involved in moving global health interventions from management boardrooms in Geneva, London, Washington, Nairobi, Bangkok and elsewhere to the many tens-ofthousands of villages and slums where Neglected Tropical Diseases persist among marginalised populations. Given recent targets set for 2020, the coming years will see many programmes expanded and scaled-up. However as this paper has shown, there are fundamental and multifaceted challenges facing planners, implementers and communities in sustainably controlling NTDs. Pre-empting and addressing these as part of a critically engaged social science research agenda is an essential aspect of good science, sound management and global ethics. The Global Report for Research on Infectious Diseases of Poverty (2012) outlined a compelling rationale for addressing gaps in implementation $[30,31]$. However such conceptually sophisticated plans themselves have barriers to uptake and diffusion related to funding priorities, expertise, the level of collaborative work between social and biomedical scientists and the ability for research to influence policy and practice [32-40].

Apart from discussing specific research areas where the social sciences can support interventions (see below for a summary), this paper also makes a number of implicit and interrelated arguments; these are supported not only by the existing NTD social science literature (including the conclusions of many of the above cited research papers) but also the wider anthropological literature on global health $[85,86,135-137]$. The first relates to the fact that, while insightful social research has certainly been conducted on many NTDs, such research continues to be relatively marginal compared to biomedically-orientated priorities and perspectives. This general lack of social inquiry on control programmes serves as a proxy for the nature of information and knowledge flows in the NTD global network. Good social inquiry engages in multidimensional ways with the complexities of a given real world problem as embedded within its socio-cultural, economic, 
political and environmental contexts. It involves spending time talking with people, asking difficult questions, challenging common assumptions, incorporating and making sense of divergent views and generating novel interpretations based on "thick descriptions". It involves understanding the local in context and as process. Such inquiry helps to transform amorphous and compliant "populations" into active "publics" who have agency, opinions and contexts that shape how they view and engage with outside plans and strategies [138]; in short, it offers the "bottom billion" a chance to become involved in global health governance and assist in setting priorities and tailoring programmes.

\section{Priority areas for social research to support NTD control}

1. Policy Processes

- How global/national policy contexts influence NTD interventions

- What institutional and organisational norms and values mediate programme operations

- The devolution of power and information sharing between partners

- Social dynamics of data generation and use

- Stakeholder incentives and drivers

- Assumptions and narratives around scaling-up

2. The Interface Between Programmes and Health Systems

- Existing resource-limitations and working norms of health systems

- Needs, capabilities and context of the primary health system and implementers

- Ways to synchronise programme goals with primary health system strengthening

- Effects of interventions on general health services

3. Community Responses to Interventions

- Access barriers, such as how geography, sub-populations and delivery schedules influence delivery

- Incentives for implementers to deliver interventions

- How local understandings of disease, livelihood patterns and other social processes influence coverage and adoption of health technologies

4. Education and Behaviour Change

- The social, cultural, political and economic barriers to behavioural changes

- Needs of differences sub-populations for tailored strategies

- How existing national programmes educate their publics

- How education strategies can move beyond small-scale, donor-funded projects to be scaled-up effectively
5. Community Involvement and Participation

- Social diversity at the community level and how it affects participatory processes

- Scope to link NTD control with wider issues in sanitation, water, primary healthcare, housing and environmental management

- Feasibility and processes involved in multi-stakeholder engagement strategies

- The shortcomings of how contemporary interventions are conceptualising and engaging communities

- The trade-offs between short-term and long-term community engagement

However in global health more generally, class and cultural barriers between global and local actors reinforce an unequal power dynamic (itself a representation of global poverty and inequality) whereby the flow of knowledge and information goes downwards from the global to the local but little evaporates upwards, at least outside epidemiological data, coverage numbers and risk factor studies [135]. If programmes are to be truly "pro-poor" then this power dynamic should be acknowledged and addressed more proactively by incorporating the voices, opinions, experiences and capacities of the "bottom billion" more explicitly into policies and programmes, and fostering more people-centric interventions. Otherwise global NTD policy narratives can begin to replicate inequality - or even colonial discourses of the "other" - by objectifying the very people they seek to assist. As noted by Vlassoff [40] more than two decades ago, tropical disease interventions can all too easily over-emphasise a narrow focus on pathogens and technologies, neglecting social perspectives.

If local realities are to be better linked to technical solutions then a re-conceptualisation among biomedical scientists, donors and ministerial officials that the "soft sciences" only provide "anecdotal" evidence, is only useful in uncovering "exotic cultural practices" and consists of "nothing but" a standardised questionnaire is needed. Despite decades of (continuing) research funding (i.e. by TDR) aimed at fostering multidisciplinary teams and collaboration between social and biomedical scientists, it is clear that the actual implementation of many contemporary NTD interventions underutilise the potential of social inquiry. Such perspectives extend far beyond the standardised "knowledge", "attitudes" and "practices" questionnaire that the social sciences are often reduced to in global health [139].

In many ways, qualitative and mixed methods research offers one of the most cost-effective research strategies for improving programme operations, if findings are readily incorporated into intervention plans and strategies. There are, of course, numerous challenges to 
seeing this type of data generated, read, considered and used in global health, including for NTDs. As one anonymous reviewer pointed out, many of the central arguments of this paper have simply reiterated points discussed since the 1970s about the relationships between the social and biomedical sciences [40]. Traditional disciplinary differences are maintained by different systems of reward and expectations, further reinforced by funding bodies and grant cycles and the socio-political nature of development institutions and organizations. Despite the rhetoric of multi-disciplinarity, it is clear that entrenched silos remain. This requires donor agencies and national governments to conceptualise new ways of conducting research and programmes to move social sciences from an afterthought to a core component of mainstream donor and national activities.

Given the large geographical areas of many programmes, social scientists should also be challenged to engage more with rapid assessment techniques to support collaborative team efforts with biomedical scientists [140]. Concerted efforts to build social science capacity in ministries and universities in endemic countries should also continue to be pursued as well as efforts to foster inter-departmental platforms. Greater reflection on how to design studies to generate an evidence-base to stimulate new people-centric intervention strategies and convince programme managers and policymakers of their practical benefits are essential, blurring the line between research and action. Reflection on the acknowledged perils of "rapid ethnography" need to be negotiated as research straddles, perhaps uneasily, the segregation of being both in and out of the public health establishment [141]. While critical perspectives offer important insights, as Kleinman [142] commented in The Lancet there is a tendency for social scientists, driven by structural systems of reward within their own epistemic communities, to valorise attacking biomedicine and public health without specifically attempting to improve it. How can social scientists remain critical but yet focused on building on, improving and working with biomedical and development actors?

My final argument relates to the influence of greater social inquiry on NTD interventions. Giving greater scope to social perspectives may drive a shift where new ways of conceptualised and implementing programmes takes place. At present, much attention on NTDs has focused on a narrative offering poverty reduction through lowcost interventions, particularly around MDA. However there are inherent trade-offs and tensions between these goals. Promises of "rapid impact packages" are likely to focus on narrow biomedical approaches that engage little with the social determinants of health and illness [10]. The value of such vertical interventions has been much debated since the Alma Ata Declaration (1978), often in highly polarised terms [137]. These tend to frame debates from an either/or perspective. Either programmes efficiently reduce the health burden of select illnesses through "narrow biomedical" approaches (or "military operations") or they improve health systems by promoting governance reforms, addressing of social determinants and citizen engagement. In the end, vertical NTD approaches offer more attractive, a-political and relatively simplified cause-effect narratives more effective in mobilise resources and amenable to conventional data reporting structures. They have also, as Molyneux and Malecela [3] correctly point out, achieved many noteworthy public health successes.

Rather the question is: how can these "cost-effective" strategies also engage in the larger challenge of addressing the under-lying drivers to neglected diseases and help build long-term societal resilience? Many of the research papers reviewed here concluded that more could have been done to link existing interventions with these broader social concerns. However, it is one thing to criticise contemporary efforts and quite another to actively engage with the conundrum of linking public health to wider developmental challenges and concerns. Focused on the Avian Influenza response in Asia, Scoones [86] has shown, in relation to his critique of the One World, One Health movement, that moving from an expertdriven, top-down approach to focus on long-term societal change is difficult to imagine, and yet still more difficult to put into practice. Global health actors navigate a complex socio-political landscape that requires framing evidence, mobilising resources and support, obtaining results and presenting data back to funding bodies to sustain activities. Broader goals, such as "improving daily living conditions" and "tackling the inequitable distribution of wealth, resources and power at the global, national and local scale" (as recommended by the WHO's Commission on the Social Determinants [26]) present somewhat of a challenge to the expectations, norms and capabilities that regulate these networks. While this may seem an obvious point, the realisation that our ever-expanding scientific knowledge-base has far outpaced our ability to effectively deal with the social determinants of disease should challenge funders, practitioners and researchers to think in more creative ways [143]. Otherwise poor populations may find that while one NTD has been eliminated, another one has simply moved in to take its place.

Beyond simplistic dichotomisations, there is much scope for disease-specific interventions to engage broadly with poverty and marginalisation, especially if we conceptualise NTD control not from the short project cycle but, as Zhang et al. [144] noted, based on a long-term commitment. This requires a shift in donor funding that emphasises engaging in larger societal and developmental processes. A number of commentaries, mostly from Latin America, have 
emphasised ways that NTD control can create synergies and collaborative programmes with other sectors to ddress the social determinants of health, including education, housing, water and sanitation, public works, agriculture, the private sector and economic development [6]. Other less expansive recommendations emphasise coupling programmes with the delivery of other health technologies, such as mosquito net distribution, nutrition programmes and vitamin A distribution [145-148]. Other opportunities exist to link the control of zoonotic diseases of poverty to agricultural development and the provision of animal health services at the community-level, as shown by the Stamp out Sleeping Sickness programme in Uganda [56].

This paper agrees with other recent critiques of global health that have emphasised the tendency for local realities to be put into the margins during planning, implementing and monitoring and evaluating interventions. Adams et al. [149] called for a movement in "slow research" to parallel the "eat locally" food movement in order to critically inspect the processes involved and their multiple associations. Also using metaphor, PanterBrick, Eggerman and Tomlinson [150] outlined what they called the need to master the four "deadly sins" of global health through a "change of heart": the coveting of silo gains, lusting after technological solutions, boasting of small successes and leaving broad promises unfulfilled. Within this wider context and critique, NTD actors have an opportunity to push boundaries and help move infectious disease control towards more resilient and sustainable pathways as envisioned in a One World, One Health agenda, not to mention influencing the post-MDG developmental agenda in dynamic, new ways [5]. Greater attention to social inquiry can help foster new ways of engagement and orientation. For this to happen, collaborative and transdisciplinary research needs to be accompanied by changes in governance structures (including funding streams) towards more flexible models that account for diversity of perspectives, seek to understand local complexities and aim to promote adaptation, reflexivity and learning over time $[151,152]$. Short project cycles that dissuade critical analysis, local capacity building and long-term engagement are problematic. In conclusion, the increased attention and funding for NTDs has the potential to alleviate some of the devastating effects of major infectious disease on the world's poor. With bold new targets established for 2020, however, it is high time that local realities and social science perspectives are put at the forefront of intervention planning.

\section{Additional file}

Additional file 1: Multilingual abstracts in the six official working languages of the United Nations.
Competing interests

The author declares that he has no competing interests.

\section{Acknowledgements}

I would like to thank the four anonymous reviewers as well as friends and work colleagues whose insightful comments and critiques have significantly improved this manuscript. This research was supported by a European Union Seventh Framework Program (FP7/2007-2013) under grant agreement $n^{\circ}$ 221948 Integrated Control of Neglected Zoonoses (ICONZ) and The University of Edinburgh Principal's Career Development PhD Scholarship and School of Social and Political Science Graduate School Scholarship. However, the funders had no role in conceiving or writing this paper and the author declares that they have no competing interests.

Received: 10 March 2014 Accepted: 16 September 2014

Published: 1 October 2014

\section{References}

1. World Health Organisation: Accelerating work to overcome the global impact of neglected tropical diseases: A roadmap for implementation. Geneva: WHO Press; 2012.

2. World Health Organisation: Sustaining the drive to overcome the global impact of neglected tropical diseases: Second WHO report on neglected tropical diseases. Geneva: WHO Press; 2013.

3. Molyneux DH, Malecela MN: Neglected tropical diseases and the millennium development goals: why the "other diseases" matter: reality versus rhetoric. Parasit Vectors 2011, 4:234.

4. Liese BH, Schubert L: Official development assistance for health-how neglected are neglected tropical diseases? An analysis of health financing. Int Health 2009, 1:141-147.

5. Smith J, Taylor EM: MDGs and NTDs: reshaping the global health agenda. PLoS Negl Trop Dis 2013, 7(12):e2529.

6. Holveck JC, Ehrenberg JP, Ault SK, Rojas R, Vasquez J, Cerqueira MT, Ippolito-Shepherd J, Genovese MA, Periago MR: Prevention, control, and elimination of neglected diseases in the Americas: Pathways to integrated, inter-programmatic, inter-sectoral action for health and development. BMC Public Health 2007, 7(1):6.

7. Chan M: Address to the Sixty-fifth World Health Assembly; http://www.who. int/mediacentre/events/2012/wha65/en/.

8. World Health Assembly: WHA66.12: Neglected Tropical Diseases: Prevention, Control, Elimination and Eradication; http://www.who.int/neglected_ diseases/mediacentre/WHA_66.12_Eng.pdf.

9. United to Combat NTDs: London declaration on neglected tropical diseases; http://unitingtocombatntds.org/downloads/press/ntd_event_london_ declaration_on_ntds.pdf.

10. Spiegel J, Dharamsi S, Wasan K, Yassi A, Singer B, Hotez PJ, Hanson C, Bundy DA: Which new approaches to tackling neglected tropical diseases show promise? PLoS Med 2010, 7(5):e1000255. doi:10.1371/journal.pmed.1000255.

11. Allen T, Parker $\mathrm{M}:$ Will increased funding for neglected tropical diseases really make poverty history? Lancet 2012, 379(9821):1097-1098.

12. Nagpal S, Sinclair D, Garner P: Has the NTD community neglected evidence-based policy? PLoS Negl Trop Dis 2013, 7(7):e2238. doi:10.1371/journal.pntd.0002238.

13. Gryseels B: Mass treatment for worms is mistaken, The Financial Times; 2006. http://www.ft.com/cms/s/0/357ca91c-72bb-11db-a5f5-0000779e2340 html\#axzz2qNLfcoDR.

14. Kabatereine NB, Malecela M, Lado M, Zaramba S, Amiel O, Kolaczinski JH: How to (or not to) integrate vertical programmes for the control of major neglected tropical diseases in sub-Saharan Africa. PLoS Negl Trop Dis 2010, 4(6)::755.

15. Kolaczinski JH, Kabatereine NB, Onapa AW, Ndyomugyenyi R, Kakembo AS Brooker S: Neglected tropical diseases in Uganda: the prospect and challenge of integrated control. TRENDS Parasitol 2007, 23(10):485-493.

16. Cavalli A, Bamba SI, Traore MN, Boelaert M, Coulibaly Y, Polman K, Pirard M, Dormael MV: Interactions between Global Health Initiatives and country health systems: the case of a neglected tropical diseases control program in Mali. PLoS Negl Trop Dis 2010, 4:e798. doi:10.1371/journal.pntd.0000798.

17. Parker $\mathrm{M}$, Allen $\mathrm{T}$ : Does mass drug administration for the integrated treatment of neglected tropical diseases really work? Assessing evidence 
for the control of schistosomiasis and soil transmitted helminths in Uganda. Health Res Pol Syst 2010, 9:3.

18. Parker $M$, Allen $\mathrm{T}$ : Will mass drug administration eliminate lymphatic filariasis? Evidence from northern coastal Tanzania. J Biosoc Sci 2013, 45:517-545.

19. Parker M, Allen T, Pearson G, Peach N, Flynn R, Rees N: Border parasites: Schistosomiasis control among Uganda's fisherfolk. J Eastern AfrStud 2013, 6:97-122.

20. Parker M, Allen T, Hastings J: Resisting control of neglected tropical diseases: dilemmas in the mass treatment of schistosomiasis and soil-transmitted helminths in northwest Uganda. J Biosoc Sci 2008 40(2):161-181.

21. Samsky A: Scientific sovereignty: How international drug donation programs reshape health, disease, and the state. Cult Anthropol 2012, 27(2):310-332.

22. Utzinger J, Raso G, Brooker S, De Savigny D, Tanner M, Ombjerg N, Singer $\mathrm{BH}, \mathrm{N}$ 'goran EK: Schistosomiasis and neglected tropical diseases: towards integrated and sustainable control and a word of caution. Parasitology 2009, 136(13):1859.

23. Landouré $A$, Dembélé $R$, Goita $S$, Kané $M$, Tuinsma $M$, Sacko $M$, Toubali $E$, French MD, Keita A, Fenwick A, Traoré MS, Zhang Y: Significantly reduced intensity of infection but persistent prevalence of schistosomiasis in a highly endemic region in Mali after repeated treatment. PLoS Negl Trop Dis 2012, 6(7):e1774.

24. Dembélé M, Bamani S, Dembélé R, Traoré MO, Goita S, Traoré M, Sidibe A Sam L, Tuinsma M, Toubali E, MacArthur C, Baker S, Zhang Y: Implementing preventive chemotherapy through an integrated national neglected tropical disease control program in Mali. PLoS Negl Trop Dis 2012, 6(3):e1574.

25. Mantilla B: The invisible plagues: a conceptual model of the neglect of neglected tropical diseases. Soc Med 2011, 6(2):118-127.

26. Marmot M, Friel S, Bell R, Houweling TA, Taylor S: Closing the gap in a generation: health equity through action on the social determinants of health. Lancet 2008, 372(9650):1661-1669.

27. Aagaard-Hansen J, Claire L: Neglected tropical diseases: equity and social determinants. In Equity, Social Determinants, and Public Health Programmes. Edited by Blas E, Anand SK. Geneva: WHO Press; 2010:135-157.

28. Allotey P, Reidpath DD, Ghalib H, Pagnoni F, Skelly WC: Efficacious, effective, and embedded interventions: implementation research in infectious disease control. BMC Public Health 2008, 8(1):343.

29. Manderson L, Aagaard-Hansen J, Allotey P, Gyapong M, Sommerfeld J: Social Research on Neglected Diseases of Poverty: Continuing and Emerging Themes. PLoSNegl Trop Dis 2009, 3(2):e332. doi:10.1371/journal.pntd.0000332.

30. WHO/TDR: Global Report for Research on Infectious Diseases of Poverty. Geneva: WHO Press; 2012.

31. WHO/TDR: Implementation research for the control of infectious diseases of poverty: Strengthening the evidence base for the access and delivery of new and improved tools, strategies and interventions. Geneva: WHO Press; 2011.

32. Manderson L: Neglected diseases of poverty. Med Anthropol 2012, 31(4):283-286.

33. Pratt $B$, Loff $B$ : Health research systems: promoting health equity or economic competitiveness? Bull World Health Organ 2012, 90(1):55-62.

34. Global Health Watch: Global Health Watch 3: An Alternative World Health Report. London, New York: Zed Books; 2012.

35. González-Block MA, Vargas-Riaño EM, Sonela N, Idrovo AJ, Ouwe-MissiOukem-Boyer O: Research capacity for institutional collaboration in implementation research on diseases of poverty. Trop Med Int Health 2011, 16(10):1285-1290.

36. Napolitano DA, Jones CO: Who needs 'pukka1 anthropologists'? A study of the perceptions of the use of anthropology in tropical public health research. Trop Med Int Health 2006, 11(8):1264-1275.

37. Kippax SC, Holt M, Friedman SR: Bridging the social and the biomedical: engaging the social and political sciences in HIV research. J Int AIDS SOC 2011, 14(2):S1

38. Albert M, Laberge S, Hodges BD, Regehr G, Lingard L: Biomedical scientists' perception of the social sciences in health research. Soc Sci Med 2008, 66(12):2520-2531.

39. Nichter M: Global health: Why cultural perceptions, social representations, and biopolitics matter. Tucson: University of Arizona Press; 2008.

40. Vlassoff C: Listening to the people: Improving disease control through social science approaches. Trans R Soc Trop Med Hyg 1992, 86:465-466

41. Espino F, Koops V, Manderson L: Community participation and tropical disease control in resource-poor settings. Geneva: WHO Press; 2004.
42. Reidpath DD, Allotey P, Pokhrel S: Social sciences research in neglected tropical diseases 2: A bibliographic analysis. Health Res Pol Syst 2010, 9(1):1

43. Allotey $P$, Reidpath DD, Pokhrel S: Social sciences research in neglected tropical diseases 1: the ongoing neglect in the neglected tropical diseases. Health Res Pol Syst 2010, 8(1):32.

44. Spiegel JM: Looking beyond the lamp post: Addressing social determinants of neglected tropical diseases in devising integrated control strategies. In The causes and impacts of neglected tropical and zoonotic diseases: Opportunities for integrated intervention strategies. Edited by National Institutes of Health. Washington: National Academies Press; 2011.

45. Parker M, Allen T: De-politicizing parasites: reflections on attempts to control the control of neglected tropical diseases. Med Anthropol 2013, 33(3):223-239.

46. Institute of Development Studies: Understanding Policy Processes: A Review of IDS Research on the Environment, Knowledge, Technology and Society Team, Institute of Development Studies, University of Sussex; 2006. http://www.ids.ac. uk/files/Policy Processes06.pdf.

47. Spiegel J, Bennett S, Hattersley L, Hayden MH, Kittayapong P, Nalim S, Wang DN, Zielinski-Gutiérrez E, Gubler D: Barriers and bridges to prevention and control of dengue: the need for a social-ecological approach. Ecohealth 2005, 2(4):273-290.

48. Egger D, Ollier E: Managing the health Millennium Development Goals: the challenge of management strengthening: lessons from three countries. Geneva: Department for Health Policy, Development and Services, World Health Organization; 2007.

49. Blundo G: Olivier de Sardan JP: Everyday Corruption and the State. Citizens and Public Officials in Africa. London: Zed Books; 2006.

50. Cairncross S, Tayeh A, Korkor AS: Why is dracunculiasis eradication taking so long? Trends Parasitol 2012, 28(6):225-230.

51. Miri ES, Hopkins RS, Ruiz-Tiben E, Keana A, Withers PC, Anagbogu IN, Sadiq LK, Kale OO, Edungbola LD, Braide E, Ologe J, Ityonzughul C: Nigeria's triumph: dracunculiasis eradicated. Am J Trop Med Hyg 2010, 83(2):215-225.

52. Ehrenberg JP, Ault SK: Neglected diseases of neglected populations: thinking to reshape the determinants of health in Latin America and the Caribbean. BMC Public Health 2005, 5(1):119

53. Rheinländer $T$, Hoat LN, Dalsgaard A, Konradsen F: Hygiene and sanitation promotion strategies among ethnic minority communities in Northern Vietnam: a stakeholder analysis. Health Pol Plan 2014, 27(7):600-612.

54. Selby R, Bardosh K, Picozzi K, Waiswa C, Welburn SC: Cattle movements and trypanosomes: restocking efforts and the spread of Trypanosoma brucei rhodesiense sleeping sickness in post-conflict Uganda. Parasites Vectors 2013, 6(1):281.

55. Fernández MG, Núñez EO, Cifuentes E: Policy analysis of the dengue control program in Mexico. Rev Saude Publica 2010, 44(6):1079-1086.

56. Bardosh K, Waiswa C, Welburn SC: Conflict of interest: use of pyrethroids and amidines against tsetse and ticks in zoonotic sleeping sickness endemic areas of Uganda. Parasit Vectors 2013, 6:204.

57. Liese B, Rosenberg M, Schratz A: Programmes, partnerships, and governance for elimination and control of neglected tropical diseases. Lancet 2010, 375(9708):67-76.

58. Buse K, Harmer AM: Seven habits of highly effective global public-private health partnerships: practice and potential. Soc Sci Med 2007, 64(2):259-271.

59. Hanson C, Weaver A, Zoerhoff KL, Kabore A, Linehan M, Doherty A, Engels D, Savioli L, Ottesen EA: Integrated implementation of programs targeting neglected tropical diseases through preventive chemotherapy: identifying best practices to roll out programs at national scale. Am J Trop Med Hyg 2012, 86(3):508.

60. Horstick O, Runge-Ranzinger S, Nathan MB, Kroeger A: Dengue vectorcontrol services: how do they work? A systematic literature review and country case studies. Trans R Soc Trop Med Hyg 2010, 104(6):379-386.

61. Madon S, Amaguru JO, Malecela MN, Michael E: Can mobile phones help control neglected tropical diseases? Experiences from Tanzania. Soc Sci Med 2014, 102:103-110.

62. Mubyazi G, Kamugisha M, Mushi A, Blas E: Implications of decentralization for the control of tropical diseases in Tanzania: a case study of four districts. Int J Health Plann Manage 2004, 19(S1):S167-S185.

63. Bardosh K, Sambo M, Sikana L, Hampson K, Welburn SC: Eliminating Rabies in Tanzania? Local Understandings and Responses to Mass Dog Vaccination in Kilombero and Ulanga Districts. PLoS Negl Trop Dis 2014, 8(6):e2935.

64. Yamey G: Scaling up global health interventions: a proposed framework for success. PLoS Med 2011, 8(6):e1001049. doi:10.1371/journal.pmed.1001049. 
65. Walt G, Shiffman J, Schneider H, Murray SF, Brugha R, Gilson L: 'Doing' health policy analysis: methodological and conceptual reflections and challenges. Health Pol Plan 2008, 23(5):308-317.

66. Gyapong JO, Gyapong M, Yellu N, Anakwah K, Amofah G, Bockarie M, Adje $S$ : Integration of control of neglected tropical diseases into health-care systems: challenges and opportunities. Lancet 2010, 375(9709):160-165.

67. Segall M: District health systems in a neo-liberal world: a review of five key policy areas. Int J Health Plann Manag 2003, 18:S5-S26.

68. Lewis D, Mosse D: Development brokers and translators: The ethnography of aid and agencies. Bloomfield: Kumarian Press; 2006

69. Mosse D: Cultivating development: An ethnography of aid policy and practice. London: Pluto Press; 2005.

70. Marchal B, Dormael M, Pirard M, Cavalli A, Kegels G, Polman K: Neglected tropical disease (NTD) control in health systems: the interface between programmes and general health services. Acta Trop 2011, 120:S177-S185.

71. WHO Maximizing Positive Synergies Collaborative Group: An assessment of interactions between global health initiatives and country health systems. Lancet 2009, 373:2137-2169.

72. Mwanakasale $V$, Songolo P, Daka V: Challenges in the control of Human African Trypanosomiasis in the Mpika district of Zambia. BMC Res Notes 2013, 6:180.

73. Baker MC, Mcfarland DA, Gonzales M, Diaz MJ, Molyneux DH: The impact of integrating the elimination programme for lymphatic filariasis into primary health care in the Dominican Republic. Int J Health Plan Manage 2007, 22:337-352

74. Meredith SE, Cross C, Amazigo UV: Empowering communities in combating river blindness and the role of NGOs: case studies from Cameroon, Mali, Nigeria, and Uganda. Health Res Pol Syst 2012, 10(1):16.

75. Pandey AP, Rathod H: Integration of leprosy in general health system vis-avis leprosy endemicity, health situation and socioeconomic development: observations from Chhattisgarh \& Kerala. Lepr Rev 2010, 81(2):121.

76. Rao PS, Gift N, Rao GS, Samuel P, Bushanam RS: Elimination of leprosy: the integration of leprosy related activities into the general health services of Tamil Nadu. Lepr Rev 2002, 73(2):123-129.

77. Asnake M, Dawit M, Ahmed A, Genebo T, Mekbib B: The involvement of the general health service staff in the management of leprosy in the Southern Region. Ethiopia Ethiop J Health Dev 1999, 13(3):187-193

78. Balen J, Liu ZC, McManus DP, Raso G, Utzinger J, Xiao S, Yu D, Zhao Z, Li Y: Health access livelihood framework reveals potential barriers in the control of Schistosomiasis in the Dongting Lake Area of Hunan Province, China. PLoS Negl Trop Dis 2013, 7(8):e2350.

79. Scott JC: Domination and the arts of resistance: Hidden transcripts. New Haven: Yale University Press; 1990

80. Scott JC: Weapons of the Weak: Everyday Forms of Peasant Resistance. New Haven: Yale University Press; 1985

81. Mpanya A, Hendrickx D, Vuna M, Kanyinda A, Lumbala C, Tshilombo V Mitashi P, Luboya O, Kande V, Boelaert M, Lefevre P, Lutumba P: Should I get screened for sleeping sickness? A qualitative study in Kasai province, Democratic Republic of Congo. PLoS Negl Trop Dis 2012, 6(1):e1467.

82. Rilkoff H, Tukahebwa EM, Fleming FM, Leslie J, Cole DC: Exploring gender dimensions of treatment programmes for neglected tropical diseases in Uganda. PLoS Negl Trop Dis 2013, 7(7):e2312

83. Omedo MO, Matey EJ, Awiti A, Ogutu M, Alaii J, Karanja DM, Montgomery SP, Secor WE, Mwinzi P: Community health workers' experiences and perspectives on mass drug administration for Schistosomiasis Control in Western Kenya: The SCORE Project. Am J Trop Med Hyg 2012, 87(6):1065-1072

84. Mondal D, Singh SP, Kumar N, Joshi A, Sundar S, Das P, Siddhivinayak H, Kroeger A, Boelaert M: Visceral leishmaniasis elimination programme in India, Bangladesh, and Nepal: reshaping the case finding/case management strategy. PLoS Negl Trop Dis 2009, 3(1):e355.

85. Biehl J, Petryna A: When people come first: critical studies in global health. Princeton University Press: Princeton; 2013.

86. Scoones I: Avian influenza: science, policy and politics. London: Earthscan; 2010.

87. Hastings JD: Rumours and riots: Local responses to mass drug administration for the treatment of neglected tropical diseases among school-aged children in Morogoro region, Tanzania. In PhD thesis. London: Brunel University, School of Social Sciences; 2013.

88. Boyd A, Won KY, McClintock SK, Donovan CV, Laney SJ, Williams S, Pilotte N, Streit T, Rochars M, Lammie P: A community-based study of factors associated with continuing transmission of lymphatic filariasis in Leogane. Haiti PLoS Negl Trop Dis 2010, 4(3):e640. doi:10.1371/journal. pntd.0000640

89. Brieger WR, Okeibunor JC, Abiose AO, Wanji S, Elhassan E, Ndyomugyenyi $\mathrm{R}$, Amazigo $\mathrm{U}$ : Compliance with eight years of annual ivermectin treatment of onchocerciasis in Cameroon and Nigeria. Parasit Vectors 2011, 4:152

90. Krentel A, Fischer PU, Weil GJ: A review of factors that influence individual compliance with mass drug administration for elimination of lymphatic filariasis. PLoS Negl Trop Dis 2013, 7(11):e2447.

91. Bhullar N, Maikere J: Challenges in mass drug administration for treating lymphatic filariasis in Papua, Indonesia. Parasit Vectors 2010, 3:70.

92. Brieger WR, Okeibunor JC, Abiose AO, Ndyomugyenyi R, Wanji S, Elhassan E, Amazigo U: Characteristics of persons who complied with and failed to comply with annual ivermectin treatment. Trop Med Int Health 2012, 17(7):920-930

93. Njomo DW, Amuyunzu-Nyamongo M, Magambo JK, Njenga SM: The role of personal opinions and experiences in compliance with mass drug administration for lymphatic filariasis elimination in Kenya. PLoS One 2012, 7(11):e48395. doi:10.1371/journal.pone.0048395

94. Muhumuza S, Katahoire A, Nuwaha F, Olsen A: Increasing teacher motivation and supervision is an important but not sufficient strategy for improving praziquantel uptake in Schistosomamansoni control programs: serial cross sectional surveys in Uganda. BMC Infect Dis 2013, 13(1):590.

95. Ramaiah KD, Vijay Kumar KN, Chandrakala AV, Augustin DJ, Appavoo NC, Das PK: Effectiveness of community and health services-organized drug delivery strategies for elimination of lymphatic filariasis in rural areas of Tamil Nadu. India Trop Med Int Health 2001, 6(12):1062-1069.

96. Taylor S: Political epidemiology: Strengthening socio-political analysis for mass immunisation - lessons from the smallpox and polio programmes. Global Publ Health: Int J Res Pol Pract 2009, 4(6):546-560. doi:10.1080/ 17441690701727850

97. Aagaard-Hansen J, Mwanga JR, Bruun B: Social science perspectives on schistosomiasis control in Africa: past trends and future directions. Parasitology 2009, 136(13):1747-1758.

98. Marx R: Social factors and trachoma: a review of the literature. Soc Sci Med 1989, 29(1):23-24.

99. Higginbotham N, Briceno-Leon $\mathrm{R}$, Johnson N: Applying health social science: Best practice in the developing world. London: Zed Books; 2001.

100. Panter-Brick C, Clarke SE, Lomas H, Pinder M, Lindsay SW: Culturally compelling strategies for behaviour change: a social ecology model and case study in malaria prevention. Soc Sci Med 2006, 62(11):2810-2825.

101. Brieger WR: Health education to promote community involvement in the control of tropical diseases. Acta Trop 1996, 61(2):93-106.

102. Khun S, Manderson L: Community and school-based health education for dengue control in rural Cambodia: a process evaluation. PLOS Negl Trop Dis 2007, 1(3):e143.

103. Burke MC: Empty Stomachs Don't Have Ears": The Role of Local Context in Shaping the Integration and Implementation of Health Education for Neglected Tropical Diseases. In PhD thesis. University of Georgia; 2010.

104. Gyorkos TW, Maheu-Giroux M, Blouin B, Casapia M: Impact of health education on soil-transmitted helminth infections in schoolchildren of the Peruvian Amazon: a cluster-randomized controlled trial. PLoS Negl Trop Dis 2013, 7(9):e2397.

105. Yuan LP, Manderson L, Ren MY, Li GP, Yu DB, Fang JC: School-based interventions to enhance knowledge and improve case management of schistosomiasis: a case study from Hunan, China. Acta Trop 2005, 96(2):248-254

106. Acka CA, Raso G, N'Goran EK, Tschannen AB, Bogoch II, Seraphin E, Tanner $M$, Obrist B, Utzinger J: Parasitic worms: knowledge, attitudes, and practices in western Cote d'Ivoire with implications for integrated control. PLoS Negl Trop Dis 2010, 4(12):e910.

107. El-Katsha S, Watts SJ: Gender, behavior, and health: schistosomiasis transmission and control in rural Egypt. Cairo: American Univ in Cairo Press; 2003.

108. Suarez RM, Olarte MR, Ana MFA, González CU: Is what I have just a cold or is it dengue? Addressing the gap between the politics of dengue control and daily life in Villavicencio-Colombia. Soc Sci Med 2005, 61(2):495-502

109. Pérez-Guerra CL, Zielinski-Gutierrez E, Vargas-Torres D, Clark GG: Community beliefs and practices about dengue in Puerto Rico. Rev Panam Salud Publ 2009, 25(3):218-226. 
110. Dransfield R, Brightwell R: Community participation in tsetse control: the principles, potential and practice. In The Trypanosomiases. Edited by Maudlin I, Holmes P, Miles M. Cambridge: CABI Publishing; 2004:533-546.

111. Ventura-Garcia L, Roura M, Pell C, Posada E, Gascón J, Aldasoro E, Munoz J, Pool R: Socio-cultural aspects of chagas disease: a systematic review of qualitative research. PLoS Negl Trop Dis 2013, 7(9):e2410.

112. Ramdas S: Cruel disease, cruel medicine: self-treatment of cutaneous leishmaniasis with harmful chemical substances in Suriname. Soc Sci Med 2012, 75(6):1097-1105.

113. Rifkin SB: Paradigms lost: toward a new understanding of community participation in health programmes. Acta Trop 1996, 61(2):79-92.

114. Abad-Franch F, Vega MC, Rolón MS, Santos WS, de Arias AR: Community participation in chagas disease vector surveillance: systematic review. PLoS Negl Trop Dis 2011, 5(6):e1207.

115. Mwanga JR, Lwambo NJ: Pre-and post-intervention perceptions and water contact behaviour related to schistosomiasis in north-western Tanzania. Acta Trop 2013, 128(2):391-398.

116. Boelee $\mathrm{E}$, Laamrani $\mathrm{H}$ : Environmental control of schistosomiasis through community participation in a Moroccan oasis. Trop Med Int Health 2004, 9(9):997-1004

117. Cairncross S, Braide El, Bugri SZ: Community participation in the eradication of guinea worm disease. Acta Trop 1996, 61(2):121-136

118. Vanlerberghe VE, Toledo ME, Rodriquez M, Gomez D, Baly A, Benitez JR, Van Der Stuyft P: Community involvement in dengue vector control: cluster randomised trial. BMJ 2009, 338:b1959.

119. Molyneux D, Hallaj Z, Keusch GT, McManus DP, Ngowi H, Cleaveland S, Ramos-Jimenez P, Gotuzzo E, Kar K, Sanchez A, Garba A, Carabin H, Bassili A, Chaignat CL, Meslin FX, Abushama HM, Willingham AL, Kioy D: Zoonoses and marginalised infectious diseases of poverty: where do we stand. Parasit Vectors 2011, 4:106.

120. Botes L, Van Rensburg D: Community participation in development: nine plagues and twelve commandments. Community Dev J 2000, 35(1):41-58

121. Cooke B, Kothari U: Participation: The new tyranny? London: Zed Books; 2001.

122. Grace D: Taking Stock: Stakeholder Assessment of Community-based Trypanosomosis Control. International Livestock Research Institute: Nairobi; 2003.

123. Brightwell B, Dransfield B, Maudlin I, Stevenson P, Shaw A: Reality vs. rhetoric-a survey and evaluation of tsetse control in East Africa. Agric Hum Values 2001, 18(2):219-233.

124. Amazigo U, Okeibunor J, Matovu V, Zoure H, Bump J, Seketeli A: Performance of predictors: evaluating sustainability in community-directed treatment projects of the African programme for onchocerciasis control. Soc Sci Med 2007, 64(10):2070-2082.

125. Amazigo UV, Leak SG, Zoure HG, Njepuome N, Lusamba-Dikassa PS: Community-driven interventions can revolutionise control of neglected tropical diseases. Trends Parasitol 2012, 28(6):231-238.

126. Emukah EC, Enyinnaya U, Olaniran NS, Akpan EA, Hopkins DR, Miri E, Amazigo U, Okoronkwo C, Stanley A, Rakers L, Richards FO, Katabarwa MN: Factors affecting the attrition of community-directed distributors of ivermectin, in an onchocerciasis-control programme in the Imo and Abia states of south-eastern Nigeria. Ann Trop Med Parasitol 2008, 102(1):45-51.

127. Katabarwa M, Habomugisha P, Eyamba A, Agunyo S, Mentou C: Monitoring ivermectin distributors involved in integrated health care services through community-directed interventions-a comparison of Cameroon and Uganda experiences over a period of three years (2004-2006). Trop Med Int Health 2010, 15(2):216-223.

128. Clemmons L, Amazigo UV, Bissek AC, Noma M, Oyene U, Ekpo U, Msuya-Mpanju J, Katenga S, Seketeli A: Gender issues in the communitydirected treatment with ivermectin (CDTI) of the African Programme for Onchocerciasis Control (APOC). Ann Trop Med Parasitol 2002, 96(1):59-74

129. Okeibunor JC, Ogungbemi MK, Sama M, Gbeleou SC, Oyene U, Remme JH: Additional health and development activities for community-directed distributors of ivermectin: threat or opportunity for onchocerciasis control? Trop Med Int Health 2004, 9(8):887-896.

130. Joshi DD, Sharma M, Waltner-Toews D: Rebuilding urban ecosystems for better community health in Kathmandu. In Ecohealth Research in Practice. Edited by Charron D. New York: Springer; 2012:191-201.

131. Alley C, Sommerfeld J: Infectious Disease in Times of Social and Ecological Change. Med Anthropol: Cross-Cult Stud Health Illness 2014, 33(2):85-91.
132. Montavon A, Jean-Richard $V$, Bechir M, Daugla DM, Abdoulaye M, Nare AB, Diguimbaye-Djaibé C, Alfarouk I, Schelling E, Wyss K, Tanner M, Zinsstag J: Health of mobile pastoralists in the Sahel-assessment of 15 years of research and development. Trop Med Int Health 2013, 18(9):1044-1052.

133. Draper AK, Hewitt G, Rifkin S: Chasing the dragon: developing indicators for the assessment of community participation in health programmes. Soc Sci Med 2010, 71(6):1102-1109.

134. McNaughton D: The importance of long-term social research in enabling participation and developing engagement strategies for new dengue control technologies. PLoS Negl Trop Dis 2012, 6(8):e1785.

135. Feierman S, Kleinman A, Stewart K, Farmer P, Das V: Anthropology, knowledge-flows and global health. Glob Publ Health 2010, 5(2):122-128.

136. Baer H, Singer M, Susser I: Medical Anthropology and the World System. Westport: Praeger; 2003.

137. Farmer P, Kim JY, Kleinman A, Basilico M: Reimagining global health. An introduction. Berkeley: University of California Press; 2013.

138. Marsland R: Who are the public in public health? Debating crowds, populations and publics in Tanzania. In Making and Unmaking Public Health In Africa: Ethnographic Perspectives. Edited by Marsland R, Prince J. Athens: Ohio University Press; 2014

139. Launiala A: How much can a KAP survey tell us about people's knowledge, attitudes and practices? Some observations from medical anthropology research on malaria in pregnancy in Malawi. Anthropol Matters 2009, 11(1).

140. Manderson L, Aaby P: An epidemic in the field? Rapid assessment procedures and health research. Soc Sci Med 1992, 35(7):839-850.

141. Parker M, Harper I: The anthropology of public health. J Biosoc Sci 2006, 38(1):1-5.

142. Kleinman A: Four social theories for global health. Lancet 2010, 375(9725):1518-1519.

143. Inhorn MC, Janes CR: The behavioural research agenda in global health: an advocate's legacy. Glob Publ Health 2007, 2(3):294-312.

144. Zhang Y, MacArthur C, Mubila L, Baker S: Control of neglected tropical diseases needs a long-term commitment. BMC Med 2010, 8(1):67.

145. Hall A, Zhang Y, MacArthur C, Baker S: The role of nutrition in integrated programs to control neglected tropical diseases. BMC Med 2012, 10(1):41

146. Blackburn BG, Eigege A, Gotau H, Gerlong G, Miri E, Hayley W, Mathieu E, Richards F: Successful integration of insecticide-treated bed net distribution with mass drug administration in Central Nigeria. Am J Trop Med Hyg 2006, 75(4):650.

147. Freeman MC, Ogden S, Jacobson J, Abbott D, Addiss DG, Jacobson J, Abbott D, Addiss D, Amnie A, Beckwith C, Cairncross S, Callejas R, Colford JM Jr, Emerson PM, Fenwick A, Fishman R, Gallo K, Grimes J, Karapetyan G, Keene B, Lammie P MacArthur C, Lochery P, Petach H, Platt J, Prabasi S, Rosenboom J, Roy S, Saywell D, Schechtman $L$, et al: Integration of water, sanitation, and hygiene for the prevention and control of neglected tropical diseases: a rationale for inter-sectoral collaboration. PLoS Negl Trop Dis 2013, 7(9):e2439.

148. Hotez PJ, Molyneux DH, Fenwick A, Ottesen E, Sachs SE, Sachs JD: Incorporating a rapid-impact package for neglected tropical diseases with programs for HIV/AIDS, tuberculosis, and malaria. PLOS Med 2006 3(5):e102.

149. Vincanne A, Burke $N$, Whitmarsh I: Slow research: thoughts for a movement in global health. Med Anthropol 2014, 33(3):179-197.

150. Panter-Brick C, Eggerman M, Tomlinson M: How might global health master deadly sins and strive for greater virtues? Global Health Action 2014, 7:23411.

151. Leach M, Scoones I, Stirling A: Dynamic sustainabilities: technology, environment, social justice. London: Earthscan; 2010.

152. Leach M, Scoones I: The social and political lives of zoonotic disease models: narratives, science and policy. Soc Sci Med 2013, 88:10-17.

doi:10.1186/2049-9957-3-35

Cite this article as: Bardosh: Global aspirations, local realities: the role of social science research in controlling neglected tropical diseases. Infectious Diseases of Poverty 2014 3:35. 